\title{
Valorização dos profissionais da educação da cidade de Campinas (2001-2004)
}

\author{
Ana Paula Kacenelenbogen Guimarães \\ Márcia Aparecida Jacomini \\ Universidade Federal de São Paulo (Brasil)
}

\section{Resumo}

Irabalho se insere no campo de estudos sobre valorização docente, tendo como objeto o processo de reestruturação da carreira do magistério público de Campinas, no período de 2001 a 2004. O objetivo é compreender e evidenciar a lógica de um poder inerente à ordem burocrática no movimento de valorização destes profissionais. Como referencial teórico, baseou-se nos trabathos de Max Weber sobre burocracia e na literatura sobre organização do magistério público. Empreendeu-se uma pesquisa qualitativa, com base na técnica de análise documental e entrevistas semiestruturadas. A presença do poder dos indivíduos investidos nos cargos burocráticos foi notada em dois aspectos: (1) na organização do magistério, no sentido de empoderamento dos especialistas e na desvalorização dos docentes, e (2) na resistência por parte dos especialistas à implementação do projeto político de valorização docente da Secretária da Educação.

Palavras-chave: Magistério público. Valorização docente. Burocracia. Município de Campinas.

\section{Appreciation of the education professionals of the city of Campinas (2001-2004)}

\section{Abstract}

The paper is inserted in the field of studies on teacher appreciation, having as object the process of career restructuring of the public teaching profession of Campinas, from 2001 to 2004. The goal is to understand and highlight the logic of an inherent power to the bureaucratic order in the movement of valorization of these professionals. As a theoretical framework, it was based on Max Weber's work on bureaucracy and the literature on the organization of public teaching profession. A qualitative research was undertaken, based on the technique of documentary analysis and semi-structured interviews. The power presence of the individuals invested in bureaucratic positions was noted in two respects: $(1)$ in the organization of education workers teaching profession, towards the empowerment of experts and in the devaluation of teachers, and (2) in the resistance by experts to the implementation of the political project of teaching appreciation by the Secretary of Education.

Keywords: Public teaching profession. Teacher appreciation. Bureaucracy. Campinas Municipality. 


\section{Apreciación de los profesionales de la educación de la cuidad de Campinas (2001-2004)}

\section{Resumen}

El artículo se inserta en el campo de estudios sobre valorización docente, teniendo como objeto el proceso de reestructuración de la carrera del magisterio público de Campinas (200 1-2004). El objetivo es comprender y mostrar la lógica de un poder inherente al orden burocrático en el movimiento de apreciación de estos profesionales. El referencial teórico se basó en trabajos de Max Weber sobre burocracia y en literatura sobre magisterio público. Se emprendió una investigación cualitativa, con base en la técnica de análisis de documentos y entrevistas semiestructuradas. La presencia del poder de los individuos invertidos en puestos burocráticos se observó en dos aspectos: (1) en la organización del magisterio, el empoderamiento de los especialistas y la devaluación de los docentes, y (2) en la resistencia de los expertos a la implementación del proyecto político de apreciación docente de la Secretaria de Educación.

Palabras clave: Magisterio público. Apreciación docente. Burocracia. Municipio de Campinas.

\section{Introdução}

A valorização docente é reconhecida como condição importante para a qualidade da educação e é tema recorrente no debate sobre as condições e possibilidades de desenvolvimento da educação pública. A aprovação de legislações que garantem padrões mínimos de valorização docente tem acompanhado, mesmo que de forma tímida, o desenvolvimento deste debate, como por exemplo a aprovação da Lei n ${ }^{\circ} 11.738$, de 16 de julho de 2008 (BRASIL, 2008), que estabelece o piso salarial nacional dos professores.

Nota-se que os governos herdam uma estrutura jurídica em relação às legislações com a qual devem conviver em suas gestões, ou seja, independentemente da plataforma política pela qual foram eleitos devem respeitar projetos e interesses passados expressos nas leis. Nas palavras de Camargo e Jacomini, vemos que

A legislação [...] é entendida como expressão da síntese dos projetos e interesses em disputa e da correlação de forças existente em cada momento histórico, ou seja, a documentação legal, de forma específica, expressa os conflitos engendrados pelos interesses diferenciados entre quem trabalha na escola (em geral, o agente da 
ação docente) e os empresariais ou governamentais (CAMARGO; JACOMINI, 2011 , p. 1311 .

Pode-se extrair disso que as alterações sucessivas de matérias relativas à educação e às condições de trabalho docente acompanham os arranjos e rearranjos de forças nos níveis federal, estadual e municipal em cada momento histórico. Nota-se, particularmente a partir da Constituição de 1988, que houve incorporações de parâmetros nas legislações de modo mais sistemático que garantem, em comparação ao passado, melhores condições de trabalho aos docentes na forma da lei. Assim, os textos legais, que foram elaborados a partir da redemocratização, passaram a expressar a necessidade e a exigência da valorização dos docentes.

No entanto, ainda segundo Camargo e Jacomini (201 1), apesar dos textos legais reconhecerem a necessidade da valorização dos docentes e exigirem a observância de estatutos e planos de carreiras nas redes de ensino, nota-se que, desde então, pouco se concretizou em termos de valorização real do trabalho docente, ainda é marcante o estigma de baixo status social dos professores da educação básica.

A pesquisa que subsidiou a redação desse artigo teve como campo empírico a gestão pública educacional do município de Campinas no mandato do Partido dos Trabalhadores (PT), entre os anos 2001 e 2004, em que estiveram à frente da Prefeitura Municipal de Campinas os prefeitos Antônio da Costa Santos e Izalene Tiene e à frente da Secretaria Municipal de Educação a Profa. Dra. Corinta M. G. Geraldi. O objetivo foi analisar o processo de apresentação e elaboração de uma proposta de valorização docente em que houve a participação dos professores e gestores (coordenadores pedagógicos, vice-diretores, diretores e supervisores) da rede municipal e da gestão da Secretaria Municipal de Educação (SME).

A análise aqui empreendida busca elucidar o embate e a articulação política da gestão municipal, com a Profa. Dra. Corinta Geraldi à frente, e os profissionais do magistério dessa secretaria na sua reformulação do plano de carreira, com foco na forma de provimento às funções de especialistas em educação. Buscou-se refletir sobre as contradições inerentes ao processo de acomodação dos diversos interesses em jogo nesse processo, em particular os interesses dos indivíduos com cargos políticos da SME, como o da Profa. Dra. Corinta Geraldi e de seu grupo político, e os interesses dos indivíduos com 
cargos na estrutura burocrática do Estado, ou seja, os funcionários públicos que ocupavam cargos de gestão. Neste aspecto, deve-se atentar, de maneira introdutória, para as diferenças essenciais entre as duas categorias de atores, cujas particularidades são determinantes à lógica de suas atuações no seio do Estado. A análise aqui empreendida caminha no sentido de se aproximar dessas particularidades, das lógicas de atuação e interesses desses atores inseridos no Estado e suas influências para a organização do magistério e a profissionalização docente.

artigo está organizado em duas seções, além dessa introdução e das considerações finais. Na primeira, discute-se brevemente a constituição da profissão docente e as características da estrutura burocrática do Estado, tendo em vista a compreensão do processo de reorganização da carreira do magistério municipal de Campinas no período de 2001 a 2004. Na segunda seção, os dados da pesquisa de campo são apresentados e analisados com foco nos conflitos gerados pela ałuação dos especialistas da educação. Nas considerações finais, além de uma síntese dos achados da pesquisa, há indicações para novos estudos.

\section{Profissionalização docente e o magistério público}

A pesquisa se enquadra numa discussão mais ampla do campo científico sobre a profissionalização docente, em que se faz a reflexão sobre os rumos da organização dos profissionais do magistério no desenvolvimento da sociedade de trabalho moderna. Oliveira (2010) defende que a profissionalização deva ser compreendida como o movimento de organização desses profissionais para transformar o trabalho docente amador em profissional, assim buscando o reconhecimento social e a valorização econômica de sua profissão. Em suas palavras,

A profissionalização do magistério pode ser compreendida como um processo de construção histórica que varia com o contexto socioeconômico a que está submetida, mas que, sobretudo, tem definido tipos de formação e especialização, de carreira e remuneração para um determinado grupo social (OLIVEIRA, 2010, p. 19). 
No entanto, considerando que se trata aqui dos profissionais do magistério da esfera pública, Oliveira (2010) chama atenção para o fato desse movimento de organização se travar em sua relação com uma forma específica de organização do Estado, a forma racional burocrática de estruturação dos serviços públicos. Se, por um lado, tem-se um movimento de professores no sentido de buscar a profissionalização e, com isso, o reconhecimento social e a valorização econômica da profissão, por outro, eles esbarram na estrutura burocrática e racional à qual se submetem por também se constituírem como servidores do Estado, a qual thes retira a autonomia sobre seu ofício (OLIVEIRA, 2010).

Max Weber é uma importante referência para se entender os aspectos da estrutura burocrática do Estado. Segundo ele, "[...] o poder, isto é, a possibilidade de encontrar obediência a uma ordem determinada, pode assentar em diferentes motivos de acatamento" (WEBER, 2005, p. 19). A legitimidade de uma ordem, ou seja, a capacidade de se fazer um grupo de indivíduos obedecer a uma ordem sem se utilizar da coerção física, segundo Weber, estrutura-se, em seus tipos puros', em três formas sociologicamente distintas: o poder tradicional, o poder carismático e, por fim, o poder legal.

$\bigcirc$ poder tradicional e carismático não nos interessam nessa análise, mas, a título de curiosidade, afirma-se que o poder tradicional, segundo Weber, provém "[...] da fé na santidade dos ordenamentos e dos poderes senhoriais desde sempre presentes. O tipo mais puro é a dominação patriarcal" (WEBER, 2005, p. 22). $\bigcirc$ conteúdo das ordens é vinculado à tradição e o poder do senhor se assenta em sua santidade. Já o poder carismático, institui-se pela confiança e dedicação afetiva à figura de uma pessoa por seus dons, podendo ser decorrente de suas "capacidades mágicas, revelações ou heroísmo, poder do espírito e do discurso [...]. Os tipos mais puros são a autoridade do profeta, do herói guerreiro, do grande demagogo" (WEBER, 2005, p. 25).

$\bigcirc$ poder legal tem como fundamento um conjunto de regras previamente estabelecidas e ordenadas. Este conjunto de regras formais são impessoais, ou seja, impostas indistintamente àqueles que estão sob seu domínio. A forma mais pura desse poder é a burocracia, que é tanto a forma da organização do Estado moderno como a de uma empresa privada. Nesse sentido, a obediência a esse poder não advém do poder atribuído a uma pessoa, mas sim de uma regra estatutária que atinge a todos. 
A estrutura burocrática é organizada hierarquicamente, as ordens partem dos níveis superiores para os inferiores. As ordens e seus acatamentos são rigorosamente regulados por regra estatutária que atinge todos os cargos da estrutura burocrática, assim como suas atribuições. Nesse sistema, é indiferente a pessoa que ocupa o cargo, pois ela deve seguir estritamente a regra estatutária que regula aquele cargo que ocupa. Nesse sentido, a melhor palavra para thes designar é individual, e não pessoa, já que suas personalidades não devem ser consideradas na estrutura burocrática.

As posições ocupadas por indivíduos dentro da estrutura burocrática, hierarquicamente organizada, seguem as exigências objetivas para cada cargo. Ou seja, as exigências são previamente regulamentadas com base nas competências necessárias e suficientes para a execução do cargo, a fim de se atingir a função pública a que destina a repartição pública.

Ainda segundo Weber (1999; 2005) a administração da burocracia é feita pelo trabalho profissional executado pelo funcionário especializado instruído, e, portanto, não é influenciada por "[...] motivos pessoais ou interferências emocionais, sem arbítrio e imprevisibilidade, sobretudo sem acepção da pessoa, de modo rigorosamente formalista, segundo regras racionais" (WEBER, 2005, p. 20).

A seleção dos funcionários é exercida por um processo formalmente regulamentado, com critérios objetivos para a seleção.

Conforme Weber (1997), a burocracia é o tipo mais puro de poder legal, no entanto, nenhum poder é exclusivamente burocrático, ou seja, administrado exclusivamente por funcionários recrutados e nomeados contratualmente. Assim, os cargos mais altos da estrutura burocrática podem ser ocupados por monarcas ou presidentes eleitos pelo povo, ou suas variantes.

Weber (1997) destaca as estreitas relações entre o Estado burocrático e o desenvolvimento do capitalismo. A moderna empresa capitalista assenta-se fundamentalmente no cálculo e seu funcionamento implica que todos seus elementos estejam racionalmente calculados, assim como ocorre no funcionamento de uma máquina. $\bigcirc$ Estado burocrático, por sua vez, acompanhando o desenvolvimento do capitalismo e suas formas de administração e controle, "[...] julga e administra segundo o direito e preceitos racionalmente estabelecidos" (WEBER, 1997, p. 41). 
A partir desse breve resumo da construção teórica de Weber sobre a burocracia, retoma-se a análise da organização do magistério público no sentido de sua profissionalização à luz das questões que envolvem a burocracia. Nesse sentido, busca-se refletir, com base em Oliveira (2010), as possíveis ambiguidades que decorrem, por um lado, da luta destes profissionais pela elevação de status de suas profissões, por outro, da defesa do magistério, enquanto servidores públicos com direitos e/ou privilégios oriundos de determinadas posições dentro da estrutura burocrática do Estado.

Com a pesquisa empírica, busca-se aprofundar numa reflexão que visa ressaltar a especificidade dos movimentos de luta dos profissionais do magistério justamente por essa categoria de atores se constituir por interesses ambivalentes. No entanto, deve-se ressaltar o estágio inicial dessas reflexões e discussões, destacando a necessidade de futuras pesquisas que abordem essa questão.

Dentro desse campo de reflexão, também deve-se ressaltar, como releva Oliveira (2010), o papel de destaque dado aos especialistas em detrimento dos professores. Os especialistas, tais como diretores e supervisores, ocupam posições superiores na hierarquia da burocracia das redes de ensino, situação que os legitima como dirigentes, enquanto os professores, posicionados no estrato inferior da organização burocrática, ficam, muitas vezes, relegados a posições de executores de ordens.

Muitas críticas e lutas dos movimentos sindicais na década de 1980 voltaram-se contra essa estruturação das burocracias de redes de ensino e contra o papel menor dado aos professores, no sentido de reduzir a diferença de "status e domínio profissionais" (OLIVEIRA, 2010, p. 30) entre os especialistas e os professores. Nas palavras da autora, "[...] as críticas à hierarquização, centralização da administração escolar e ao modelo burocrático e centrado nas especializações levaram à consolidação de outras referências de gestão educacional, inscrita na Constituição Federal de 1988" (OLIVEIRA, 2010, p. 30).

Weber (1997) também endossava em seus escritos a preocupação com relação ao crescimento do poder das burocracias, em especial o de alguns burocratas, questionando-se quais seriam as forças que poderiam controlar e limitar o mecanismo crescente de poder da burocracia, ou seja, quais seriam as forças que garantiriam e preservariam as liberdades e a democracia. Weber acreditava e apostava em um equilíbrio oriundo de instituições políticas, 
de representantes eleitos pela população que cumprissem uma função de liderança política e propusessem uma política positiva. Em suas palavras, "[...] um parlamento ativo [...] [é aquele] que supervisiona a administração [burocrática] participando continuamente do trabalho desta" (WEBER, 1997, p. 64).

Dessa concepção de Weber (1997), pode-se pensar as questões relativas à organização da educação pública numa rede municipal de ensino, diante de um movimento de manutenção de privilégios corporativistas, a manutenção do poder proveniente da organização burocrática, e buscar alternativas para prevalecer os interesses da sociedade para a educação pública e para o trabalho docente e sua valorização.

Com essa breve reconstituição de temas caros à discussão do movimento dos profissionais do magistério em prol de sua profissionalização e, portanto, de sua valorização, e da reflexão sobre burocracia estatal, intenta-se posicionar os objetivos da pesquisa neste amplo campo de análise.

Na seção seguinte, os elementos da pesquisa empírica que interessam particularmente são aqueles que dão tonalidade e vivacidade à discussão teórica exposta. $\bigcirc$ poder da burocracia como um conceito sociológico, nos textos de Weber, influencia os embates reivindicatórios por melhores condições de trabalho, valorização docente e defesa da profissionalização? $\bigcirc$ poder dos representantes políticos eleitos exerce um contrapeso ao poder inerente da burocracia ou funcionários de carreira? Como se dão as relações entre essas duas fontes de poder nas negociações pela valorização docente?

Nesse sentido, a partir de experiências empíricas, busca-se avançar numa discussão teórica, ainda que incipiente, no campo científico de políticas educacionais, sobre o embate entre atores em cargos políticos e em cargos da estrutura burocrática no movimento pela profissionalização e valorização docente.

Apesar dos conflitos e tensões, nos quatro anos da gestão da SME de Campinas pelo Partido dos Trabalhadores se construiu um plano para o desenvolvimento das condições de trabalho docente e reorganização da carreira do magistério (professores e especialistas). Um contexto promissor para análises sobre os temas mencionados foi institucionalizado na Lei $n^{\circ} 12.012$, de 29 de junho de 2004 (CAMPINAS, 2004). 


\section{Debates e embates na reorganização da carreira docente do município de Campinas}

Para realização da pesquisa, as pesquisadoras se aproximaram dos embates entre o grupo político eleito para o mandato de 2001 a 2004 para a Prefeitura Municipal de Campinas, com a Profa. Dra. Corinta Geraldi como secretária de educação, e os servidores públicos da mesma secretaria. Particularmente, aqueles com cargos mais altos, como os diretores e supervisores. Foram realizadas entrevistas semiestruturadas e leitura dos documentos oficiais produzidos no período estudado, tais como publicações da SME, anais dos Congressos Municipais de Educação, publicações no Diário Oficial e publicações de outros órgãos oficiais.

Nas entrevistas semiestruturadas, apesar da produção de um roteiro de perguntas, considerou-se que o acompanhamento muito restrito ao roteiro de questões poderia atrapalhar e desviar os entrevistados daquilo que consideravam importante e significativo no processo em questão. Tal entendimento se apoiou em Michelat (1980).

As entrevistas foram realizadas majoritariamente entre os professores da Rede Municipal de Ensino de Campinas (RMEC), pois a pesquisa originalmente se focava neste grupo de profissionais. À medida que se evidenciava a relevância dos especialistas no processo de reestruturação da carreira do magistério, constatou-se a dificuldade de encontrá-los, por se tratar de pessoas de uma geração mais antiga de funcionários da RMEC, cuja maioria se aposentou há quase duas décadas. As informações sobre os especialistas foram supridas por documentos da RMEC e pela tese de Oliveira (2005).

No total, foram seis entrevistas com professores da RMEC, incluindo uma entrevista com a então secretária de educação, a Profa. Dra. Corinta M. G. Geraldi. Dois dos entrevistados fizeram parte da gestão da SME apenas por um período. As entrevistas levaram, em média, uma hora e meia.

Uma parte dos resultados da pesquisa empírica decorre de informações não esperadas no início da pesquisa, que foram surgindo naturalmente ao longo das entrevistas, configurando-se, devido à sua recorrência ao longo das entrevistas, em situações significativas para o processo estudado. Além disso, contribuíram para o entendimento do funcionamento da própria Rede Municipal de Ensino (RME) no que se refere à força do corporativismo e das relações de poder instituídas neste espaço, denominadas pelos entrevistados 
de "a polêmica dos especialistas" e mantidas neste texto. Assim, serão apresentados e discutidos os conteúdos das entrevistas e do estudo documental relacionados a este aspecto do processo de reestruturação da carreira do magistério da cidade de Campinas no período de 2001 a 2004.

O olhar para esta polêmica, para o modo como ela se instaurou e o modo como se desenvolveu, é interessante, sobretudo, para a compreensão do embate entre os atores políticos e os atores da estrutura burocrática. A presença desta polêmica na memória dos envolvidos denota realmente um caráter sintomático a respeito do processo de discussão das modificações das condições de trabalho docente, levantando questões tocantes, por exemplo, ao corporativismo assim como à repulsa à identidade do professor e sua relação com a forma que se estrutura a carreira do magistério.

A polêmica dos especialistas consistiu-se em um episódio marcado por fortes tensões e resistências à alteração das regras, estabelecidas pelo estatuto do magistério de 1991, de provimento aos cargos de especialistas (orientador pedagógico, vice-diretor, diretor e supervisor). $\bigcirc$ estatuto previa o concurso de acesso para o provimento de cargos de especialistas, permitindo que, cumprindo os requisitos específicos de cada cargo, um professor prestasse o concurso interno, um concurso em que apenas os professores da Prefeitura de Campinas poderiam concorrer, para ocupar o cargo de orientador pedagógico ou vice-diretor, da mesma forma que estes últimos podiam prestar o concurso para ocupar o cargo de diretor educacional ou de coordenador pedagógico, e, por fim, estes para o cargo de supervisor (CAMPINAS, 1991).

Por este mecanismo, criou-se, dentro da hierarquia da rede municipal de educação, um sistema de ascensão de cargos de magistério e elevação no stałus e no salário a cada progressão. Sem que os servidores passassem por um concurso público de prova e títulos. Para ilustrar este mecanismo de ascensão rotineira na RME, transcreve-se uma pequena parte de uma das entrevistas.

Que lá atrás, nos anos [19]90, [19]91, [19]92 [...] estabelecia o quê? Uma estrutura de carreira, que, na verdade, a gente não pode dizer que é uma carreira, era uma estrutura que estabelecia que você entrava como professor e depois você tinha acesso a um concurso interno para ser vice-diretor ou orientador pedagógico, depois você trabalhava mais um pouco e podia prestar outro concurso interno para ser diretor ou coordenador pedagógico, passava mais uns anos e você podia prestar para supervisor. Então, era 
uma carreira de ascensão de um professor até um supervisor. Se você quisesse ganhar mais, você tinha que fazer essa carreira, esse percurso, isso foi lá no começo dos anos 90, que foi estabelecido assim (ENTREVISTADO 2, 2018 ).

No entanto, diante o entendimento expresso da Constituição Federal e da Lei de Diretrizes e Bases da Educação Nacional (BRASIL, 1996; 1988) de que a investidura em cargo público dependia de aprovação de concurso público de provas ou de provas e títulos, o acesso aos cargos de especialistas por concurso de acesso apenas não seria conflitante com as legislações federais pós-1988 se considerasse como carreira única a de professores e especialistas. No entanto, conforme Oliveira, apesar do Estatuto do Magistério Público de Campinas inicialmente tratar a carreira dos professores e especialistas como única, "[...] sua redação explicita claramente duas carreiras funcionais diferentes: uma de docentes, outra de especialistas" (2005, p. 246). Nesse sentido, o ingresso no cargo de especialista, pelo entendimento dado em 1988 pela CF, deveria ser realizado por meio de concurso público de ingresso.

As tentativas de adequar o estatuto do magistério público de Campinas aos parâmetros da Constituição Federal de 1988 ensejaram, na década de 1990 e início de 2000, intensas resistências por parte dos profissionais do magistério da RME. Conforme Ganzelli (2000), Maria Helena Guimarães e Castro, que assumiu a Secretaria Municipal de Ensino de Campinas (SME), no ano de 1993 e permaneceu até dezembro de 1994, exonerou-se do cargo em decorrência de conflitos com os funcionários da SME gerados, dentre outros motivos, por sua tentativa de alterar o estatuto do magistério.

Ao longo da década de 1990, a situação da falta de professores efetivos na RME se acirrou $A$ inadequação do estatuto do magistério às legislações federais, somada à rotina de substituição dos cargos de especialistas por professores, impossibilitou, juridicamente, a abertura de novos concursos públicos. Isso provocou a falta de professores efetivos em sala de aula, que era em parte compensada pela contratação de temporários. Em 1999, segundo Oliveira (2005), o Ministério Público do Trabalho questionou a contratação de 700 professores em caráter temporário.

Alguns trechos das entrevistas evidenciaram a dimensão do problema da falta de professores na RME de Campinas no início de 2000, dando uma 
noção sobre o que a gestão da SME, que assumiu em 2001, precisou que enfrentar.

Tinha uma vacância no cargo de especialistas, que chega[va] a $70 \%$. Então estavam todos fora da sala de aula, substituindo vice, direção, OP. Inclusive porque o salário era significativamente maior, dos quadros de gestão. [...] A única maneira de você ganhar mais era [se tornando especialista] (ENTREVISTADO 3, 2017).

No final desta década, ainda conforme Oliveira (2005), retomou-se a discussão a partir de uma proposta de estatuto enviada pela Secretaria de Educação às escolas com o objetivo de se discutir a contemporaneidade do estatuto do magistério frente à Constituição Federal de 1988 e à Lei de Diretrizes e Bases da Educação Nacional. Já nesta ocasião, ficou explícito que as opiniões divergentes entre os profissionais do magistério se polarizavam, de acordo com a autora, entre duas propostas: os que defendiam a existência de concursos públicos abertos a quem quisesse participar para provimento dos cargos de especialistas, "[...] como já fazia na rede estadual e como queria o caráter constitucional [...]", e os que defendiam a permanência do concurso de 12 acesso, "dando preferência aos profissionais que já estavam nas funções de especialistas sob a condição de substitutos" (BRASIL, 2005, p. 245).

No primeiro ano da gestão do Partido dos Trabalhadores na prefeitura, a SME consultou a Câmara de Educação Básica (CEB), órgão do Conselho Nacional de Educação (CNE), sobre a possibilidade de se continuar a execução dos concursos de acesso.

A resposta do Conselho Nacional de Educação (CEB 032/200 1) definiu que as ascensões aos cargos de carreira de especialista, admitidas pelo sistema jurídico nacional, só seriam permitidas antes da Constituição Federal de 1988. Estariam vetadas depois disso.

Estatuto do Magistério de 1991, com suas regulamentações e omissões, criava, na prática, uma estrutura, na rede municipal de Campinas, de modo que a única forma que os professores vislumbravam evoluir "na carreira"2 , em termos de aumento salarial, era se lançarem aos cargos de especialista, que, em comparação ao salário de professor, era muito superior. A facilidade do professor da RME de acessar tais cargos em decorrência de uma disputa interna, ou seja, de um fechamento à concorrência externa, como seria se houvesse um concurso público e como estabelecia a CF/88, contribuía para que 
este mecanismo fosse defendido por aqueles que se beneficiavam dele e se tornasse um mecanismo usual na RME.

A tabela abaixo mostra os vencimentos do cargo de professor e dos cargos de especialistas, assim como a diferença entre o vencimento dos especialistas em comparação com o vencimento dos professores. Os valores foram corrigidos para o ano de 2002.

\section{Tabela 1}

Vencimentos dos cargos do Magistério e percentual correspondente a diferença entre o vencimento do Professor III $^{3}$ e dos especialistas, em jun/2002

\begin{tabular}{|c|c|c|}
\hline Cargos & $V_{\text {Vencimentos }}^{4}(\mathrm{R} \$)$ & $\begin{array}{l}\text { Diferença entre } \\
\text { vencimentos }\end{array}$ \\
\hline Professor III & $1.550,46$ & - \\
\hline Orientador pedagógico & $2.355,99$ & $52 \%$ \\
\hline Vice-diretor & $2.355,99$ & $52 \%$ \\
\hline Diretor educacional & $2.740,62$ & $76 \%$ \\
\hline Coordenador pedagógico & $2.740,62$ & $76 \%$ \\
\hline Supervisor educacional & $3.190,97$ & $106 \%$ \\
\hline
\end{tabular}

Fonte: Guimarães com base em Campinas (2000; 2002); calculadora do Banco Central do Brasil.

Considerando tais condições dadas pela legislação municipal, muitos professores buscavam maior valorização salarial por meio dos concursos de acesso aos cargos de especialista, ou, na falta destes (o último havia ocorrido em 1993), da simples substituição, que era um mecanismo ainda mais facilitado, regulados "unicamente [por] portarias de substituições" |OLIVEIRA, 2005, p. 234).

Um outro motivo presente, além do aumento salarial, e mencionado nas entrevistas, particularmente na fala da ex-secretária, era a noção de que o trabalho em sala de aula era desgastante devido ao conjunto das condições precárias de trabalho docente e ao status inferior da categoria de professor.

Dessa forma, os professores que ocupavam há anos a função de especialistas não queriam voltar ao seu cargo de professor não apenas pela 
questão financeira, mas também pela identidade profissional e status social da profissão docente. Havia, segundo os entrevistados, uma repulsa do "ex-professor" em se reconhecer como professor. Nesse sentido, professores que já não estavam mais em sala de aula há muito tempo viam o retorno ao cargo de professor como algo vergonhoso.

[...] aí vem um ranço que tem a ver com esses ódios que a gente está vendo hoje...É um ódio sabe? Os especialistas diziam assim 'eu nunca vou me rebaixar a ser professor' como se, ser professor fosse uma coisa menor, tinha uns que estavam só acostumados a mandar, [alguns diziam] 'mas eu nem sei ser professor'... [e eu falava] 'você é um professor, você é educador...como não sabe? Se não sabe peça demissão, pois esse é seu cargo, é esse que você entrou na rede' (GERALDI, 2018).

A forma como, de um lado, a legislação municipal e, de outro, a ineficácia política com que o poder executivo municipal enfrentava o poder dos especialistas manteve uma estrutura de ascensão de um cargo a outro como mecanismo análogo a uma progressão na carreira, contribuindo para aprofundar a concepção de que o retorno ao cargo de professor seria um rebaixamento na carreira. Nota-se, então, que o baixo status social da profissão docente é reforçado por uma estrutura hierárquica de cargos do magistério em que o patamar inferior é o cargo de professor e, pior, que o único caminho de progressão possível é o abandono da atividade docente. Tal estrutura de "carreira" nas palavras de uma professora entrevistada,

[...] tinha uma rede com uma defasagem de profissionais, [...] professores, que substituíam e saíam do seu cargo. E eram muitos que saíam e estavam há muito tempo nesse cargo de orientação pedagógica, ou de vice-direção, e que na cabeça deles tinha uma certa ideia de poder, como se 'eu sou mais do que o cargo de professora' (ENTREVISTADO 5, 2018, grifo nosso).

Nesse sentido, embora a forma de provimento aos cargos de especialistas mediante concurso de acesso estivesse em desarmonia com a Constituição Federal de 1988 e a Lei de Diretrizes e Bases da Educação Nacional de 1996, o poder que os especialistas tinham dentro da SME conduzia para uma realidade em que esta estrutura de progressão na carreira e os cargos assumidos mediante este mecanismo se tornassem um direito na sua percepção. 
Quando a Profa. Dra. Corinta M. G. Geraldi assumiu a SME, em 2001 , buscou reformular esta estrutura de ascensão na carreira do magistério, com o objetivo de diminuir a desvalorização à qual os professores estavam submetidos e cessar a designação dos professores que estavam exercendo a função de gestores, fazendo com que retornassem aos seus cargos de direito, buscando resolver o problema da falta de professores da RME. Nas palavras da ex-Secretária Profa. Dra. Corinta M. G. Geraldi,

Tinha mais de mil professores fora de lugar, tinha professor trabaIhando nas Obras, no Turismo, na Câmara de Vereadores [...] [e] substituindo... Tinha diretor funcionando como Supervisor, tinha Vice[-Diretor] como Diretor e tinha Professor como Vice e OP. Então, na sala de aula ficavam professores substitutos, que, a cada mês, quando um voltava [formava] aquela escada toda (GERALDI, 2018).

Estas iniciativas no início da gestão estavam alinhadas à sua concepção de escola e da educação pública. A Profa. Dra. Corinta M. G. Geraldi e seu grupo político, em consonância com projetos e práticas educacionais progressistas, tais como o Movimento de Reorientação Curricular, em São Paulo, na gestão Paulo Freire; Escola Plural, em Belo Horizonte; Escola Candanga, em Brasília; e Escola Cidadã, em Porto Alegre viam a escola como um espaço em que os alunos (crianças, jovens e adultos) são os protagonistas, os professores são os mediadores a partir de um trabalho autoral e o governo responde pelo suporte (pedagógico, material, administrativo, legal e financeiro) (GERALDI, 2004).

A partir dessa concepção, percebe-se a pertinência das políticas públicas propostas no sentido de valorizar o docente. Os professores deveriam ter condições para promover um trabalho docente livre e autoral dentro da escola para que os conhecimentos universalmente acumulados sejam direcionados e adaptados à situação concreta dos alunos e de seu contexto, não bastando a reprodução deste conhecimento, como muitas vezes se faz num modelo de escola tradicional.

Conforme informações extraídas das entrevistas, particularmente da própria ex-secretária e dos professores que compuseram sua equipe num primeiro momento, entendia-se a urgência da SME em adequar o estatuto do magistério à carreira e à forma de ingresso, de modo a se tornar constitucional 
e, assim, publicar novos concursos públicos para sanar o problema da falta de profissionais do magistério. No entanto, a revolta e a resistência formada por parte dos especialistas se impôs como um fator determinante no processo.

Diante disso, a administração da SME tomou medidas para abertura das discussões em 7 de julho de 2001, com a criação do Fórum dos Representantes das Unidades Educacionais de Campinas, responsável por se reunir mensalmente para discutir e apresentar propostas sobre a organização da carreira do magistério público municipal para, no final daquele ano, apresentar o texto guia a ser submetido à votação da plenária do II Congresso Municipal de Educação5, que seria realizado no final do ano de 2001 . Além da inclusão dos servidores do magistério no processo de formulação das propostas sobre as carreiras, buscava-se, conforme informações dos entrevistados informar e esclarecer os professores e especialistas da RME da necessidade de alteração da progressão carreira e principalmente de sua forma de provimento por se apresentar em desarmonia com a Constituição Federal de 1988 (ENTREVISTADO 2, 2017 ; ENTREVISTADO 4, 2017 ; CORINTA, 2018).

Ao longo do segundo semestre de 2001, se desenharam três propostas de reestruturação da carreira no Fórum dos Representantes, denominadas 16 de propostas A, B e C (CAMPINAS, 2001). A proposta B, "concurso de promoção", era a defendida pela SME, que se contrapunha à estrutura de carreira em vigor e ao consequente processo de desvalorização do professor; a proposta C, de eleição dos cargos de especialistas, era defendida por um pequeno grupo de professores da RME, que compartilhavam ideais político-partidários e eram mais envolvidos e comprometidos com as questões da RME. A proposta $A$, " $[\ldots]$ concurso público para especialistas", era tida como "plano B $[\ldots]^{\prime \prime}$, caso as outras não fossem aceitas na plenária. Esta proposta previa uma carreira para cada cargo: professor, coordenador, vice-diretor, diretor e supervisor, com concurso público de prova e títulos para os cargos iniciais de cada carreira.

A proposta B, defendida pela SME, propunha que todos entrassemna carreira como professor por meio de concurso público de provas e títulos, seria uma carreira única (CAMPINAS, 2001). O professor nunca deixaria de ser professor, mas poderia ocupar outras funções dentro da RME, como a função de orientador pedagógico, vice-diretor, diretor, coordenador pedagógico e supervisor, evoluindo na carreira conforme assumisse tais funções, mas sempre, ao final de um período determinado, voltaria à sala de aula. Essa proposta 
tinha o objetivo de enfrentar diretamente o problema da desvalorização do professor, problema esse reforçado pela estrutura de progressão na carreira exercida pelos profissionais do magistério da RME em que a forma mais efetiva de buscarem aumento salarial era o abandono da sala de aula.

A proposta $C$, defendida por um grupo de professores da RME, baseava-se na eleição para os cargos de especialista, ou seja, todos ingressariam na carreira única de professor por meio de concurso público de prova e títulos, podendo exercer as funções de especialistas caso se submetessem ao processo de eleição e fossem eleitos (CAMPINAS, 2001).

A discussão das propostas apresentadas no texto guia e depois no Il Congresso Municipal de Educação, com a participação direta de 5 mil servidores da SME, não chegou ao fim, estendendo para o primeiro semestre de 2002 a decisão sobre a carreira do magistério da RME (ENTREVISTADO 2, 2017).

A resistência dos especialistas que seriam "prejudicados" com qualquer uma das três propostas se intensificou no primeiro semestre de 2002, particularmente após a submissão, em quatro de fevereiro de 2002, de um projeto de lei de autoria da SME à Câmara dos Vereadores de Campinas para a votação da proposta de carreira única de professor.

A resistência ao projeto de lei submetido à Câmara foi tão intensa que, ao final do semestre, mesmo depois de encontros do Fórum de Representantes para tratar exclusivamente das propostas da carreira e do convite da SME para esclarecimento de dúvidas sobre o projeto de lei, não se conseguiu dissolver a onda de desinformações, em certa medida, influenciada pelo descontentamento dos especialistas. Então, a prefeitura desistiu do projeto de lei e publicou o edital para concurso para especialistas em 6 de junho de 2002, encerrando a discussão sobre a carreira única. Assim, ficou estabelecido que a carreira não seria única a despeito da intenção do grupo político à frente da SME. Nas palavras de Geraldi:

Nós bancamos uma decisão, [...] tinha uma carreira inconstitucional que queria um concurso único para cargos diferentes, não podia ter, nós propusemos uma carreira única para manter um concurso único, que era o que eles queriam, eles não queriam um concurso único, pois não aceitavam ser chamados de professor e disseram 'se querem fazer concurso então façam um concurso para cada cargo'. Então, está bom, se é assim que vocês querem, então 
vai ser um concurso para cada cargo, e foi feito um concurso para cada cargo, só que eles não acharam que nós teríamos coragem de fazer um concurso para cada cargo, pois isso é não ter carreira, carreira continuada, cada cargo é um cargo, não tem continuidade de um cargo para outro, professor é professor do início ao fim da vida, o supervisor do início ao fim da vida, se quiser, mudar de cargo tem que fazer novo concurso público. Eu não acho que isso era o melhor, que até acho que, para ser supervisor, era bom ser primeiro professor. Mas essa foi a alternativa que os especialistas nos deixaram, eles não aceitaram ser chamados de professor e eles pensaram que a gente não teria coragem de fazer...e tentaram até o fim desbancar na justiça, mas a justiça não desbancou, pois era legal. Um concurso por cargo... cada cargo é um cargo, do ponto de vista constitucional e legal, era correto, não era melhor para uma carreira de continuidade na história do magistério que tinha em Campinas. Digamos assim que intransigência foi contra [...] ser [chamado] de professor (GERALDI, 2018, grifo nosso).

Os dados ilustram um retrato da situação na década de 1990 do magistério no município de Campinas, no qual, de um lado, apresentam-se os professores em condições de trabalho precárias, e com um baixo valor sim-

18 bólico da profissão, e, de outro, os especialistas com melhores remunerações, melhores articulações e um maior status profissional.

Constatou-se, em seguida, que essas diferenças atribuídas a esses dois grupos de profissionais do magistério, somada à facilidade de ascensão do grupo mais vulnerável, criam raízes para a perpetuação desta situação. Em decorrência desse processo, acentua-se a diferença entre o poder desses grupos, acarretando na dificuldade da reversão dessa estrutura já que esse mecanismo vai fortalecendo o grupo de indivíduos dos estratos mais altos da hierarquia burocrática a ponto de se chocar com os projetos políticos dos representantes eleitos, como foi o caso da secretária da educação da gestão analisada, a Profa. Dra. Corinta Geraldi.

\section{Considerações Finais}

A influência da burocracia na elaboração de políticas públicas educacionais é um campo de pesquisa muito promissor se considerarmos que a educação pública no Brasil é oferecida em redes de ensino que são 
organizações burocráticas, nas quais os profissionais do magistério estão inseridos.

Diante da ambiguidade destes profissionais apresentada por Oliveira (2010), em que, se, por um lado, assumindo a identidade profissional defendem o aumento de seu status profissional, por outro, como funcionários públicos lidam com outras questões, particulares à ordem burocrática, ressaltam-se dois questionamentos: o primeiro se refere ao fato da categoria de "profissionais do magistério" não ser uma categoria homogênea para se pensar o movimento de profissionalização desses trabalhadores, por ser um grupo que apresenta interesses diversos em decorrência de estarem submetidos aos níveis hierárquicos distintos. Neste contexto, ao serem tratados como grupo, é preciso considerar que há interesses conflitantes.

segundo questionamento se refere à necessidade de aprofundar a análise da categoria dos professores e ao seu movimento de profissionalização sob a ótica dessa ambiguidade, do fato de além de professores serem também funcionários públicos inseridos numa burocracia, e, portanto, estarem sob influências e lógicas de organização diferentes.

Uma compreensão mais aprofundada sobre os efeitos dessa peculiaridade, na qual a maioria dos professores da educação básica se encontra, pode trazer descobertas reveladoras para a compreensão do desse movimento de organização. Na pesquisa que subsidiou a redação deste artigo, percebeu-se que os professores estão inseridos numa estrutura burocrática e situados num baixo nível hierárquico. Isso explica o fraco movimento de organização dos professores na defesa de sua valorização profissional. Apesar dessa não ser a única explicação, configurou-se como um elemento importante.

Nesse sentido, ressalta-se que o movimento de profissionalização dos professores, de modo específico, e a organização dos professores, de modo geral, deve considerar o contexto das burocracias, as relações internas, os níveis hierárquicos, sua lógica interna, a valorização dos aspectos técnicos em detrimento dos políticos, os critérios objetivos dos ocupantes dos cargos etc.

Por fim, retomando Weber, é importante lembrar seu receio quando comparou o desenvolvimento da burocracia a uma máquina, pressentindo o perigo das burocracias modernas em se fortalecer progressivamente em função de uma autogestão, sem haver um controle externo com poder de contenção. No caso da educação e na pesquisa empírica aqui realizada notou-se que 
as iniciativas voltadas ao desenvolvimento da educação pública, tendo como porta-vozes prejuízos pelo embate com forças que visavam a manutenção de privilégios decorrentes da alta posição na hierarquia burocrática.

Nesse sentido, iniciativas que visavam a valorização docente, como a implementação da carreira única, para aumentar a autonomia do professor- pesquisador e fortalecer a relação professor/aluno foi derrotada pela força de grupos ocupantes de cargos nos níveis superiores da hierarquia da burocracia da Secretaria da Educação, seguindo interesses provenientes da organização burocrática.

Mesmo que Weber tivesse razão no sentido de apresentar a política e seus representantes como uma força limitante ao poder cada vez maior e mais independente das grandes burocracias, esta análise empírica mostrou que, apesar de limitar em parte o poder burocrático, os sujeitos em posse dos cargos políticos não conseguiram implementar a carreira única, cujo objetivo era a valorização docente, o fortalecimento e autonomia do trabalho docente.

\section{Notas}

1 Max Weber utiliza em suas explicações sociológicas tipos puros, mas são conceitos que não existem de forma pura na realidade, trata-se de um recurso teórico.

2 Optou-se em redigir "carreira" entre aspas, pois, apesar de se tratar, em termos legais estabelecidos pelo Estatuto do Magistério, de duas carreiras, a dos professores e a dos especialistas, em termos práticos, as mudanças de cargos se executavam como se estivessem dentro de uma carreira.

3 Formação em graduação licenciatura plena.

4 Valor da remuneração estabelecida pelo edital $001 / 2000$ para o cargo de professor III corrigida pelo índice INPC (IBGE) para jun/2002.

5 O। Congresso Municipal de Educação ocorreu em 1991.

\section{Referências}

BRASIL. [Constituição de [1988]. Constituição da República Federativa do Brasil. Brasília: Diário Oficial [da] União da República Federativa do Brasil, Poder Executivo, Brasília, DF, 5 de outubro 1988. Seção 1, p. 1. 
BRASIL. Lei $\mathbf{n}^{\circ} \mathbf{9 . 3 9 4}$, de $\mathbf{2 0}$ de dezembro de 1996. Estabelece as diretrizes e bases da educação nacional. Brasília, 1996. Disponível em: http://www.planalto.gov.br/ccivil_03/ leis/19394.htm. Acesso em: 23 maio 2019.

BRASIL. Lei $\mathbf{n}^{\circ} \mathbf{1 1 . 7 3 8}$, de 16 de julho de 2008. Regulamenta a alínea "e" do inciso III do caput do art. 60 do Ato das Disposições Constitucionais Transitórias, para instituir o piso salarial profissional nacional para os profissionais do magistério público da educação básica. Disponível em: http://www.planalto.gov.br/ccivil_03/_ato2007-2010/2008/ lei/11 1738.htm. Acesso em: 23 maio 2019.

CAMARGO, Rubens Barbosa; JACOMINI, Márcia Aparecida. Carreira e salário do pessoal docente da Educação Básica: algumas demarcações legais. Educação em Foco, Belo Horizonte, v. 14, n. 17, p. 129-167, jul. 2011.

CAMPINAS. Lei $\mathbf{n}^{\circ} \mathbf{6 . 8 9 4}$, de $\mathbf{2 4}$ de dezembro de 1991. Dispõe sobre o estatuto do magistério público e dá providências correlatas. Disponível em: https://bibliotecajuridica.campinas. sp.gov.br/index/visualizaratualizada/id/84717. Acesso em 05 de maio 2018.

CAMPINAS. Concurso Público de Provas e Títulos para provimento do cargo de professor. Edital n $001 / 2000$. [Suplemento] Diário Oficial [do] Município de Campinas, Poder Executivo, Campinas, 18 de abril 2000, p. 1.

CAMPINAS. Comunicado sobre os textos conclusivos do Il Congresso Municipal de Educação de Campinas, 21 de novembro de 2001. Diário Oficial [do] Município de Campinas, Poder Executivo, Campinas, 22 de novembro 2001, p. 8.

CAMPINAS. Concurso Público de Provas e Títulos para provimento do cargo de especialistas, 05 de junho de 2002. Diário Oficial [do] Município de Campinas, Poder Executivo, Campinas, 6 de junho. 2002, p. 12.

CAMPINAS. Lei $\mathbf{n}^{\circ} \mathbf{1 2 . 0 1 2}$, de $\mathbf{2 9}$ de junho de 2004. Dispõe sobre a criação e transformação de cargos na administração direta, no hospital municipal Dr. Mário Gatti e na Fumec, reestrutura o plano de carreiras da prefeitura municipal de campinas, instituído pela Lei municipal n 8.340 de 26 de maio de 1995, e dá outras providências. Disponível em: https:// bibliotecajuridica.campinas.sp.gov.br/index/visualizaratualizada/id/85942. Acesso em: 25 abr. 2018.

CONSELHO NACIONAL DE EDUCAÇÃO (Brasil). Parecer CNE/CEB 0032/2001, de 05 de novembro de 2001 . Consulta sobre o Estatuto do Magistério Público. Brasília, DF, 2001. Disponível em:

http://portal.mec.gov.br/index.php?option=com_docman\&view=download\&alias=6799. Acesso em: 25 abr. 2018. 
GERALDI, Corinta Maria Grisolia. Entrevista. Campinas (São Paulo), 22 maio 2018.

ENTREVISTADO 2. Entrevista. Campinas (São Paulo), 8 nov. 2017.

ENTREVISTADO 3. Entrevista. Campinas (São Paulo), 15 nov. 2017.

ENTREVISTADO 4. Entrevista. Campinas (São Paulo), 9 nov. 2017.

ENTREVISTADO 5. Entrevista. Campinas (São Paulo), 15 maio 2018.

GANZELI, Pedro. O processo de construção da gestão escolar no município de Campinas: 1983/1996. 2000. 238 f. (Tese de Doutorado) - Programa de Pós-Graduação em Educação, Universidade Estadual de Campinas, 2000.

GERALDI, Corinta Maria Grisolia. Escola Viva: Política educacional por uma escola contra a barbárie. In: GERALDI, Corinta Maria Grisolia; RIOLFI, Claudia Rosa; GARCIA, Maria de Fátima (Org.). Escola Viva: elementos para a construção de uma educação de qualidade social. Campinas: Mercado de Letras, 2004.

MICHELAT, Guy. Sobre a utilização da entrevista não-diretiva em sociologia. In: THIOLLENT, Michel (Org.). Crítica metodológica, investigação social e enquete operária. São Paulo: Polis, 1980.

22 OlIVEIRA, Dalila. Os trabalhadores da educação e a construção política da profissão docente no Brasil. Educar em Revista, Curitiba, n. 1, p. 17-35, 2010. (Número especial).

OLIVEIRA, Regina Maringoni. A Secretaria Municipal de Educação de Campinas (20012004) contribuições para o entendimento da Escola Viva. 2005, 529f. (Tese de Doutorado) - Programa de Pós-Graduação em Educação, Universidade Estadual de Campinas, 2005.

WEBER, Max. Parlamentarismo e governo numa Alemanha reconstruída. In: WEBER, Max. Textos selecionados. São Paulo: Editora Nova Cultural, 1997.

WEBER, Max. Economia e Sociedade: fundamentos da sociologia compreensiva. Brasília: Editora Universidade de Brasília, 1999.

WEBER, Max. Três tipos de poder e outros. Lisboa: Tribuna da História, 2005. 
Grupo de Estudo e Pesquisa Política Educacional e Gestão Escolar (Geppege) Política Educacional e Gestão Escolar (Geppege) ORCID ID: https: / / orcid.org/0000-0002-1998-8819 E-mail: ana.kace@gmail.com

Profa. Dra Márcia Aparecida Jacomini Universidade Federal de São Paulo Departamento de Educação Programa de Pós-Graduação em Educação da Escola de Filosofia, Letras e Ciências Humanas da Unifesp Coordenadora do Grupo de Estudo e Pesquisa em Política Educacional e Gestão Escolar (Geppege) ORCID ID: https: / / orcid.org/0000-0003-2936-3174 E-mail: jacominimarcia@gmail.com.br

Recebido 12 jul. 2019

Aceito 11 set. 2019 